\title{
Coordinately Express Hemicellulolytic Enzymes in Kluyveromycesmarxianus to Improve the Saccharification and Ethanol Production From Corncobs
}

\author{
Qing Lan \\ Fudan University \\ Yitong Duan \\ Fudan University \\ Pingping Wu \\ Fudan University \\ Xueyin Li \\ Fudan University \\ Yao Yu \\ Fudan University
}

Bo Shi

Chinese Academy of Agricultural Sciences

Jungang Zhou ( $\square$ zhoujg@fudan.edu.cn )

Fudan University https://orcid.org/0000-0001-9618-1683

Hong Lu

Fudan University

\section{Research}

Keywords: Kluyveromyces marxianus, hemicellulases, ribosomes skipping, enzymatic hydrolysis, ethanol

Posted Date: January 25th, 2021

DOl: https://doi.org/10.21203/rs.3.rs-151980/v1

License: @ (i) This work is licensed under a Creative Commons Attribution 4.0 International License. Read Full License 


\section{Abstract}

Background:

Hemicelluloses act as one factor contributing to the recalcitrance of lignocelluloses that prevent cellulases to degrade the cellulose efficiently even in low quantities, and supplement of hemicellulases can enhance performance of commercial cellulases in the enzymatic hydrolyses of lignocellulose. $K$. marxianu is an attractive yeast for cellulosic ethanol fermentation, since it has remarkable thermotolerance, high growth rate, and broad substrate spectrum etc, as well as a promising host for heterologous protein production. In this study, we attempted to coordinately express multiple hemicellulases in Kluyveromyces marxianus through a 2A-mediated ribosomes skipping to self-cleave polyproteins, and investigated their capabilities for saccharification and ethanol production from corncobs.

Results

Two polycistronic genes IMPX and IMPaX were constructed to test the self-cleavage efficiency of P2A sequence from Foot and Mouth Disease virus (FMDV) in $K$. marxianus. The IMPX gene consisted of a $\beta$ mannanase gene $M 330$ (without the stop codon), a P2A sequence and a $\beta$-xylanase gene $X y n-C D B F V$ in turn, while in the IMPaX gene there was an additional a-factor signal sequence fused at the N-terminus of $X y n-C D B F V$. The extracellular $\beta$-mannanase activities of IMPX and IMPaX strains were 21.34 and 15.50 $\mathrm{U} / \mathrm{mL}$ repectively. By contrast, the IMPaX strain secreted $136.17 \mathrm{U} / \mathrm{mL} \beta$-xylanase, which was much higher than that of IMPX strain, $42.07 \mathrm{U} / \mathrm{mL}$. Based on these, two recombinant strains, the IXaR and IMPaXPaR, were constructed to coordinately and secretorily express the $\beta$-D-xylosidase RuXyn1 and XynCDBFV, or three hemicellulolytic enzymes including M330, Xyn-CDBFV and RuXyn1. The IMPaX strain produced 1664.2 and $0.90 \mathrm{U} / \mathrm{mL}$ of extracellular $\beta$-xylanase and $\beta$-xylosidase, while the IMPaXPaR strain secreted $159.8,2210.5$, and $1.25 \mathrm{U} / \mathrm{ml}$ of $\beta$-mannanase, $\beta$-xylanase, and $\beta$-xylosidase in fed-batch fermentations respectively. Hemicellulolytic enzymes of these two strains enhanced the releases of both glucose and xylose from diluted acid pretreated corncobs when acted synergistically with commercial cellulases. In hybrid saccharification and fermentation (HSF) of pretreated corncobs, hemicellulases of the IMPaXPaR strain increased about $34.2 \%$ and $11.1 \%$ of ethanol productions at 144 and $216 \mathrm{~h}$ respectively .

Conclusions

The FMDV P2A sequence showed high efficiency in self-cleavage of polyproteins in $K$. marxianus, and could be used for secretory expression of multiple enzymes in present of their own signal sequences. The IMPaXPaR strain that coexpressed three hemicellulolytic enzymes could be used as a consolidated bioprocessing (CBP) strain for ethanol production from lignocelluloses.

\section{Background}


Lignocellulose is the most abundant renewable resource on earth, which is recalcitrance and compact biomass that composes of directly interlinked cellulose, hemicelluloses and lignin [1]. Utilization of lignocellulosic biomass is a feasible solution to avoid the excessive reliance on fossil fuels, and alleviates the global warming and environmental pollution events [2]. Unlike first-generation biofuels used edible feedstock, cellulosic ethanol is manufactured from non-edible carbohydrates contained in plant cell walls, basically composing of four phases that include pretreatment, hydrolysis, fermentation, and dehydration [3]. Among these, hydrolysis (saccharification) of pretreated lignocelluloses is a critical prerequisite for ethanolic fermentation by microbes, but usually these two processes can be concurrently integrated into one step known as simultaneous saccharification and fermentation (SSF) when using enzymes to hydrolyze cellulose and hemicellulose into fermentable sugars [4].

To depolymerize lignocelluloses into fermentable sugars, at least three types of cellulases, such as $\beta-1,4-$ endoglucanase, exocellobiohydrolase, and $\beta$-1,4-glucosidase, and more diversity of hemicellulases including $\beta-1,4$-xylanase, $\beta-1,4$-xylosidase, $\beta-1,4$-mannanase, $\alpha$-arabinosidases, and esterases etc are required to act synergistically [5]. But the less catalytic efficiency and high cost of enzymes made the cellulose hydrolysis become the major bottleneck for bringing down the production cost of biofuel from lignocelluloses [6, 7]. A consolidated bioprocessing (CBP) strategy that integrated enzyme production, saccharification, and fermentation in one step is well accepted as an attractive approach to reduce the cost of biofuel production [8]. However, the conflict of optimal temperatures within saccharification and fermentation can decrease the efficiency of lignocellulose hydrolysis. To circumvent this problem, a hybrid saccharification and fermentation (HSF) is set out by hydrolyzing pretreated lignocelluloses with commercial cellulases before a CBP process $[9,10]$.

CBP microbes for cellulosic ethanol production were genetically modified from either natural cellulolytic bacteria, such as Cellulolytic thermophiles, Caldicellulosiruptor bescii, and Thermoanaerobacterium saccharolyticum etc, and filamentous fungi, such as Trichoderma sp., Aspergillus sp., Fusarium oxysporum, and Penicillium sp. etc, or ethanologenic microorganisms including Saccharomyces cerevisiae, K. marxianus,Zygosaccharomyces bailii and Zymomonas mobilis, by a combination of cellulase production, enzymatic hydrolysis, and microbial fermentation into a single operation $[11,12]$. But the low ethanol tolerance is an actual inferiority of cellulolytic microbes, since distillation of ethanol is an energy-intensive process and it consumes more of heat to separate ethanol from a lower concentration fermentation $[13,14]$. Co-fermentation of pentoses, xylose and arabinose, is a reasonable way to raise the bioethanol concentration from lignocellulosic biomass and reduce the cost of cellulosic ethanol as well [15]. As the most utilized yeast for ethanol fermentation, S. cerevisiae is unable to assimilate xylose and other $\mathrm{C} 5$ sugars, which impedes the efficient ethanol conversion from lignocellulose, even with efficient glucose fermentation and high ethanol productivity and tolerance [16]. K. marxianus is regarded as another attractive yeast for ethanolic fermentation due to its abilities of fastest growth, remarkable thermotolerance, and broad substrate spectrum including glucose, mannose, galactose, lactose, cellobiose, the pentose sugars xylose and arabinose, which virtually presented in all enzymatic hydrolysates of pretreated lignocelluloses [17-20]. Factually, either in SSF or HSF, high- 
temperature fermentation can significantly elevate the efficiency of lignocellulose hydrolysis, decrease the risk of contamination, and curtail the ethanol production phase $[4,21]$.

To be ethanologenic CBP strains, saccharification enzymes were required to simultaneously express in one host to convert cellulose into fermentable sugars, while the genetic basis of $K$. marxianus less well understood than S. cerevisiae, [22]. A synthetic biology technique termed as "Promoter-based Gene Assembly and Simultaneous Overexpression (PGASO)" was developed to integrate gene cassettes in the genome of $K$. marxianus $\mathrm{KY} 3$ in a single step, with each gene expression regulated by an individual promoter along with a terminator [23]. Unfortunately, the double homologous recombination frequency was very low in K. marxianus, even flanking with long homologous fragments [24]. On the contrary, it has a high activity of non-homologous end-joining (NHEJ) that can efficiently integrate non-homologous DNA fragments into chromosome via fusing two DNA strands together in the absence of specific sequences $[25,26]$. In the present study, we incorporated a different way for coexpression of multiple hemicellulases using a P2A self-processing peptide form foot-and-mouth disease virus (FMDV) in K. marxianus. P2A sequences are relatively short oligopeptides located between the $\mathrm{P} 1$ and $\mathrm{P} 2$ proteins in some picornavirus viruses, and it can undergo an enzyme-independent self-cleavage at its own $\mathrm{C}$ terminus during protein translation, enabling the ribosome skipping to the next codon to continue the translation [27-29]. By assembling a $\beta$-mannanase M330 gene and a $\beta$-xylanase Xyn-CDBFV gene into a single ORF with FMDV $\mathrm{P} 2 \mathrm{~A}$ [30], the efficiency of P2A self-cleavage in secretory expression of multiple enzymes in $K$. marxianus was evaluated. Furthermore, we also investigated the capability of enzyme mixtures to improve the hydrolysis of corncobs and ethanol production by the recombinant $K$. marxianus strain.

\section{Methods}

Strains and plasmids

The $K$. marxianus Fim-1 $\triangle U R A 3$ strain is uracil auxotrophic that derived from FIM-1 deposited in China General Microbiological Culture Collection Center (CGMCC No.10621). The expression plasmid pUKDN132 was constructed as described previously [19].

Expression plasmids constructions and transformations

A polycistronic gene M330-Xyn-CDBFV (hereafter termed the IMX gene) that the $\beta$-xylanase gene Xyn$C D B F$ was fused to the $C$ terminus of the $\beta$-mannanase gene $M 330$ directly was constructed as described below. The M330 gene was amplified from the pZP41plasmid by the primers MF and IMXR1 (Table 1), and the XYn-CDBFV gene was amplified with IMXF and XR from a pET21a/Xyn-CDBFV [31]. After purification with a SanPrep Column DNA Gel Extraction Kit (B518131, Sangon Biotech, Shanghai, China), the two PCR fragments were ligated together by Gibson assembly [32], and then used as a template to amplify the fused hybrid gene IMX with the primers MF and XR. The resulting PCR amplicon was ligated with the Spe I and Not I linearized pUKDN132 by Gibson assembly, and generated the plasmid pUKDN132/IMX. 
Two polycistronic genes $I M P X$ and $I M P a X$ that contained P2A sequence alone or along with a signal sequence of $S$. cerevisiae a-factor between the $M 330$ and the $X y n-C D B F V$ were also constructed. The $P 2 A$ sequence was added to the $3^{\prime}$ terminus of $M 330$ by PCR using the primers MF and IMPR. The Xyn-CDBFV sequence was amplified by the primer pair IMPXF/XR, and ligated with the $P 2 A$ fused $M 330$. After that the full-length $I M P X$ was amplified by the primers MF and XR, and then inserted into the pUKDN132, obtaining the pUKDN132/IMPX plasmid. When assembling the IMPaX gene, the a-factor signal sequence was amplified from the plasmid pPIC9 (Invitrogen, USA) using the primers PaF1 and aXR1, and the Xyn$C D B F V$ sequence was amplified by the primers aXF1 and XR from the pET21a/Xyn-CDBFV. Three fragments including the $P 2 A$ fused $M 330$, a-factor signal sequence, and $X y n-C D B F V$ were ligated together to assemble the polycistronic gene IMPaX as described above. After cloned into pUKDN132, the resulting plasmid was then termed pUKDN132/IMPaX.

The polycistronic IMPaXPaR gene that integrated three genes into a single ORF was constructed by assembling the IMPaX lack of the stop codon TAG with a $P 2 A$ linked a-factor signal sequence and a $\beta$ xylosidase RuXyn 1 gene. The IMPaX fragment and $P 2 A$ linked a-factor signal sequence was amplified from pUKDN132/IMPaX by the primer pairs, MF/XPR and XPaF/aR1, respectively, while the RuXyn1 gene was amplified from a pET21/RuXyn1 vector using the primers aRF and RR [33]. These three fragments were ligated by Gibson assembly to get the full length of IMPaXPaR. After PCR amplification with the primers MF and RR, the IMPaXPaR was inserted into the Spe I/ Not I site of pUKDN132 to obtain the plasmid pUKDN132/IMPaXPaR. The plasmid pUKDN132/IXPaR were constructed by was amplified an XPaR fragment from pUKDN132/IMPaXPaR by the primers IXF and RR, and then inserted into the Spel/Not I site of pUKDN132.

For plasmids transformations, the $K$. marxianus Fim- $1 \triangle U R A 3$ was inoculated in $5 \mathrm{ml}$ YPD medium ( $1 \%$ Yeast Extract, $2 \%$ Peptone, $2 \%$ Glucose), and cultured at $30^{\circ} \mathrm{C}, 200 \mathrm{rpm}$ for $20 \mathrm{~h}$. Yeast cells were collected by centrifugation, and all plasmid transformations were conducted according to the method by Antunes et al [34]. Transformants were then selected on SD plates containing $0.67 \%$ YNB, $2 \%$ glucose, and $2 \%$ agar.

\section{Enzymatic assays}

The activity of $\beta$-mannanase was determined with $0.5 \%$ locust bean gum (G0753, Sigma-Aldrich, USA) in $50 \mathrm{mM}$ acetate buffer $\mathrm{pH} 5.5$ at $68^{\circ} \mathrm{C}$ [35]. Quantitative assays of $\beta$-xylanase were performed using $1 \%$ wheat arabinoxylan (P-WAXYL, Megazyme, Bray, Ireland) buffered with $50 \mathrm{mM}$ acetate $\mathrm{pH} 5.5$ at $50^{\circ} \mathrm{C}$ [31]. $\beta$-xylosidase activities were measured using $p$-nitrophenyl- $\beta$-D-xylopyranoside as we described previously [33]. One unit $(U)$ of enzyme activity was defined as the amount of enzyme releasing $1 \mu \mathrm{mol}$ of reducing sugars or $p$-nitrophenol per minute.

Western blot assays

Transformants were grown in YG mediums ( $2 \%$ yeast extract, $4 \%$ glucose) at $30{ }^{\circ} \mathrm{C}, 200 \mathrm{rpm}$ for $72 \mathrm{~h}$. One milliliter of cultures was harvested, and centrifuged for $10 \mathrm{~min}$ at $5,000 \mathrm{rpm}$ to detect the secretory or 
intracellular expression of enzymes by Western blot. To prepare lysate samples, collected cells were suspended in $1 \mathrm{~mL}$ lysis buffer (50 mM HEPES pH 7.5, $140 \mathrm{mM} \mathrm{NaCl}, 1 \mathrm{mM}$ EDTA, 1\% Triton X-100, 0.1\% $\mathrm{Na}$-Deoxycholate), and then disrupted by a bead-beater (FastPrep-24, MP, California, USA) at $6 \mathrm{~m} / \mathrm{s}$ for 2 min with $400 \mu \mathrm{L}$ acid-washed glass beads (G8772, Sigma-Aldrich, Missouri, USA). Western blots were carried out using an Anti-His Tag antibody (M30111, Abmart, Shanghai, China) and a horseradish peroxidase-conjugated goat-anti-mouse secondary antibody (074-1806, KPL, USA) as previously described [19].

\section{Fed-batch fermentations}

All fermentations were performed in $5 \mathrm{~L}$ bioreactors (BXBIO, Shanghai, China) with an initial working volume of $1.5 \mathrm{~L}$ as described previously [19]. Inoculum seeds were precultured in Erlenmeyer flasks containing $150 \mathrm{~mL}$ YD medium at $30^{\circ} \mathrm{C}, 220 \mathrm{r} / \mathrm{min}$ for $18 \mathrm{~h}$. After sterilization and cooling, temperatures of the bioreactors were set to $30^{\circ} \mathrm{C}$. Batch fermentations were started by inoculating with $150 \mathrm{~mL}$ inoculum seeds. After glucose was completely depleted, concentrated mediums consisting of $600 \mathrm{~g} / \mathrm{L}$ glucose, $5 \mathrm{mg} / \mathrm{L}$ biotin, $100 \mathrm{mg} / \mathrm{L}$ calcium pantothenate, and $100 \mathrm{mg} / \mathrm{L}$ Niacin, were fed into the reactors at rates of $20-35 \mathrm{~mL} / \mathrm{h}$ depending on the dissolved oxygen (DO), which should be maintained above $10 \%$. The pHs were controlled automatically at 5.5 with ammonium hydroxide. Samplings at given intervals were determined for cell densities $\left(\mathrm{OD}_{600} \mathrm{~nm}\right)$, wet cell weights $(\mathrm{WCW})$, and enzymes activities.

\section{Pretreatment of the corncobs}

Corncobs, purchased from Bei Piao Bang Bang Corncob Development Company (Beijing, China), were ground to a particle size range of 0.25-0.45 mm (40-60 meshes), and immersed in an aqueous solution of $2 \%$ diluted sulfuric acid at a solid-to-liquid $\left(\mathrm{S} / \mathrm{L}\right.$ ) ratio of $1: 5$. The mixtures were autoclaved at $121^{\circ} \mathrm{C}$ for 1 h. After neutralization with $0.1 \mathrm{~N} \mathrm{NaOH}$, diluted acid pretreated corncobs were separated by filtration, washed with deionized water, and dried at $80^{\circ} \mathrm{C}$.

Enzymatic saccharification and fermentation

Enzymatic saccharifications were performed in $150 \mathrm{~mL}$ Erlenmeyer flasks with $2 \mathrm{~g}$ pretreated corncobs in $20 \mathrm{~mL}$ of $50 \mathrm{mM}$ sodium citrate buffer $\mathrm{pH} 5.5$. The corncobs slurries were autoclaved at $121^{\circ} \mathrm{C}$ for 30 min. After addition of 5 FPU CTec2 per g corncob or coupled with $300 \mu \mathrm{L}$ supernatant of the Fed-batch fermentation cultures, the flasks were stirred in an air incubator shaker at $45^{\circ} \mathrm{C}, 150 \mathrm{rpm}$. At given intervals, hydrolysates were sampled for sugar analyses.

HSFs were conducted in $150 \mathrm{~mL}$ flasks containing $10 \mathrm{~g}$ of the diluted acid pretreated corncobs with 11.5 $\%$ moisture content. The corncobs were immersed in $80 \mathrm{~mL}$ of $50 \mathrm{mM}$ sodium citrate buffer $\mathrm{pH} 5.5$ and autoclaved at $121^{\circ} \mathrm{C}$ for 20 min. Following sterilization, 10 FPU CTec2 per gram corncob was added and enzymatic saccharifications were performed at $45^{\circ} \mathrm{C}, 150 \mathrm{rpm}$. After $72 \mathrm{~h}, 10 \mathrm{~mL}$ of filter-sterilized media $\left(20 \mathrm{~g} / \mathrm{L} \mathrm{KH}_{2} \mathrm{PO}_{4}, 20 \mathrm{~g} / \mathrm{L}\left(\mathrm{NH}_{4}\right)_{2} \mathrm{SO}_{4}, 10 \mathrm{~g} / \mathrm{L} \mathrm{MgSO} 4 \cdot 7 \mathrm{H} 2 \mathrm{O}, 5 \mathrm{~g} / \mathrm{L}\right.$ yeast extract, and $\left.1 \mathrm{~g} / \mathrm{L} \mathrm{MnSO}_{4}\right)$ [4] and 1 $\mathrm{mL}$ of fed-batch cultures collected at $48 \mathrm{~h}$ were added to the corncobs slurries. Sterile deionized water 
was supplemented to make $100 \mathrm{~mL}$ of the total liquid. The flasks were incubated at $30{ }^{\circ} \mathrm{C}$ without stirring, and samples were taken every $24 \mathrm{~h}$ for analysis of glucose, xylose, and ethanol.

Analytical methods

Reducing sugars were determined by the DNS method [36]. HPLC analyses of glucose, xylose, xylitol, and ethanol were performed using a MetaCarb $87 \mathrm{H}$ column $(300 \times 7.8 \mathrm{~mm}$ ) (Agilent, USA) with a refractive index detector at $35{ }^{\circ} \mathrm{C}$. Twenty microliters of each sample were injected and eluted with $0.01 \mathrm{~N} \mathrm{H}_{2} \mathrm{SO}_{4}$ in water at a rate of $0.6 \mathrm{~mL} / \mathrm{min}$ for $30 \mathrm{~min}$.

\section{Results And Discussion}

Self-cleavages of polyprotein with FMDV P2A in K. marxianus

Due to the chemical diversity in structure of hemicelluloses that are heterogeneous polysaccharides with both linear and branched molecules cross-linked to cellulose microfibrils, complete degradation requires multiple hemicellulases to act synergically [37]. Aiming to facilely express multiple enzymes in ethanologenic $K$. marxianus for the hemicellulose degradation, we resorted to a 2A-mediated ribosomes skipping for co-translational cleavage of the polyprotein. The 2A-mediated cleavage is a common phenomenon in eukaryotic cells that it skips the synthesis of a glycyl-prolyl peptide bond at the Cterminus of 2A, releases the nascent protein, and resumes the downstream translation [38]. While the efficiency of 2A self-cleavage is strongly related ot the sequence contexts of upstream and downstream ORFs in the polycistrons [39]. Given that we tested the efficiency of FMDV P2A self-cleaving in $K$. marxianus by expression of three polycistronic genes IMX, IMPX, and IMPaX (Fig1a and b). The IMX gene consisted of a M330 coding sequence (INU1 signal peptide+mature protein coding sequence) and a Cterminal 6xHis-tagged Xyn-CDBFV mature protein coding sequence fused in-frame directly. In the IMPX gene, the P2A sequence was incorporated between M330 and Xyn-CDBFV without stop codon. The IMPaX gene had an extra a-factor signal sequence between P2A and Xyn-CDBFV. These three polycistronic genes were all cloned into the vector pUKDN132, in which their expressions were all driven by an INU1 promoter from K. marxianus.

After cultured in flasks, expressions of M330 and Xyn-CDBFV were detected by measuring the activities $\beta$ mannanase and $\beta$-xylanase in both supernatants and cell lysates of the IMX, IMPX, and IMPaX strains, which were transformed with the plasmids pUKDN132/IMX, pUKDN132/IMPX, and pUKDN132/IMPaX, respectively. Unexpectedly, as a control, we observed that the IMX strain produced high activities of both $\beta$-mannanase and $\beta$-xylanase in the supernatant, with approximately $24.03 \mathrm{U} / \mathrm{ml}$ and $155.26 \mathrm{U} / \mathrm{ml}$ respectively (Table 2), suggesting that these two genes fused directly did not impair their catalytic activities. This double-activities of the IMX strain provided a good reference to the P2A effect on the expression of downstream Xyn-CDBFV. The extracellular $\beta$-mannanase activities of IMPX and IMPaX strains were about 21.34 and $15.50 \mathrm{U} / \mathrm{mL}$ respectively, which were slightly lower than that of the IMX 
strain, whereas the intracellular activities of M330 in the two strains were higher, inferring that fusion of Xyn-CDBFV to the C-terminus of M330 with P2A slightly decreased the secretory expression of M330.

In our constructs, the efficiency of FMDV P2A self-cleavage was related to the production of Xyn-CDBFV. Enzymatic determinations demonstrated that the IMPaX strains secreted $136.17 \mathrm{U} / \mathrm{mL} \beta$-xylanase into the supernatants, and retained $39.43 \mathrm{U} / \mathrm{mL}$ intracellularly. By contrast, the supernatant $\beta$-xylanase of IMPX strain was $42.07 \mathrm{U} / \mathrm{mL}$, which was far less than the intracellular activity $87.59 \mathrm{U} / \mathrm{mL}$. To confirm whether the $\beta$-xylanase activities of IMPX and IMPaX strains were the self-cleavaged Xyn-CDBFV by the 2A-mediated ribosomes skipping during translation, these samples were further analyzed by SDS-PAGE and Western blot. As shown in figure 1c and e, protein bands with approximate $57 \mathrm{kDa}$ molecular weight in the supernatants of IMX strain were in accord with the theoretical prediction of the fusion protein IMX. In both supernatants of the IMPaX and IMPX strains, M330 and Xyn-CDBFV were secreted alone, while the secretory Xyn-CDBFV of IMPaX strain was much higher than that of the IMPX strain, suggesting that, in the presence of P2A and a-factor signal sequence, Xyn-CDBFV could be secreted to medium more efficiently. This result was in agreement with the previous literature [40]. Furthermore, western blot assays for the His-tagged Xyn-CDBFV in the above samples were in compliance with the enzymatic assays and SDS-PAGE above (Fig $1 \mathrm{~d}$ and $\mathrm{f}$ ). Thus, to extracellularly express two proteins via FMDV P2A selfcleavage, an extra signal sequence should be included at the $\mathrm{N}$-terminus of downstream gene. The $2 \mathrm{~A}-$ mediated ribosomal 'skipping' is an attractive alternative to the internal ribosomal entry site (IRES), first identified in the encephalomyocarditis virus, since it can express multiple cistrons at equimolar levels [41]. However, in our results, we also found that this ribosomal 'skipping' in co-translation would decrease in apparent the total protein express levels, especially for the downstream gene.

Coexpression of hemicellulolytic enzymes with FMDV P2A

Hemicelluloses act as one important factor contributing to the recalcitrance of lignocelluloses, and they, even in low quantities, can prevent cellulases to degrade the cellulose efficiently [42]. Cellulase supplemented with endoxylanase promoted the hydrolysis of steam-exploded feed stocks, released more glucose, accumulated higher content of xylobiose and xylooligosaccharides [43,44]. Content of xylose, however, was not significantly elevated, which may be due to the insufficient $\beta$-xylosidase in most cellulase enzymes produced by filamentous fungi Trichoderma reesei $[5,45]$. We reasoned that an ethanologenic strain co-expressed multiple hemicellulases, especially $\beta$-xylanase and $\beta$-xylosidase, would eliminate the accumulation of xylooligosaccharides and produce more fermentable xylose. A $\beta$ xylosidase RuXyn1 that has high capability of converting intermediate xylo-oligosaccharides into xylose was used to co-express with $\beta$-xylanase in $K$. marxianus [33]. The RuXyn1 coding sequence was fused to Xyn-CDBFV with a P2A and an a-factor signal sequence (Fig. 2a), and the resulting IXPaR was expressed in $K$. marxianus under the unique INU1 promoter. The IXPaR strain transformed with the pUKDN132/IXPaR produced 59.01 and $0.05 \mathrm{U} / \mathrm{ml}$ of extracellular $\beta$-xylanase and $\beta$-xylosidase in flask cultures respectively (Fig $2 \mathrm{~b}-\mathrm{d}$ ). 
Supplements of $\beta$-mannanase facilitated the total enzymatic hydrolysis of lignocellulose feedstock and brewery's by-product, such as beech sawdust, spruce, Douglas fir wood and chips spent grain [46-49]. Given critical roles of $\beta$-mannanase, $\beta$-xylanase and $\beta$-xylosidase in the hydrolysis of lignocellulose, we tested the feasibility of P2A for coordinately expressing these three selected enzymes in one ORF. The polycistronic gene IMPaXPaR that compacted M330, Xyn-CDBFV and RuXyn1 into one ORF, each with a signal sequence (Fig. 2a). Consistent with that of the IMPaX and IXPaR strains, all activities of these three enzymes were detectable in the crude culture supernatant of the IMPaXPaR strain, which is obtained by transformation of the pUKDN132/IMPaXPaR plasmid. The $\beta$-mannanase, $\beta$-xylanase and $\beta$ xylosidase activities were 18.90, 61.00, and $0.07 \mathrm{U} / \mathrm{mL}$, respectively (Fig. 2c-e). As expected, figure $2 \mathrm{~b}$ showed three protein bands in culture supernatants of the IMPaXPaR strain that were corresponding to the molecular weights of M330, Xyn-CDBFV and RuXyn1, confirming that FMDV P2A is applicable for secretory co-expression of multiple enzymes in K. marxianus.

Preparation of hemicellulolase mixtures by recombinant $K$. marxianus strains

We have previously developed a high-cell density fed-batch fermentation for single hemicellulolytic enzyme production in K. marxianus [19]. In this study, we evaluated the productions of multiple enzymes in fed-batch fermentation for both the IXPaR and IMPaXPaR strains. K. marxianus is Crabtree negative yeast that does not perform aerobic alcoholic fermentation, and but can respire even in high glucose concentrations [50,51]. However, high concentration of glucose could adversely cause respiratory repression and turn to alcoholic fermentation especially in high-cell density, probably due to the insufficient oxygen supply. Similar to $S$. cerevisiae, a Crabtree positive yeast that predominantly produces ethanol in high glucose even in sufficient oxygen levels, it is practicable to guide $K$. marxianus to utilize glucose for respiratory metabolism and convert carbon resources into cell biomass, as glucose can be fed slowly to maintain a concentration below the threshold value in fed-batch fermentation [52, 53]. Additionally, ethanol fermentation could affect cell growth in $K$. marxianus, and thus decreases expressions of enzymes. To circumvent this, we controlled the dissolved $\mathrm{O}_{2}$ above $10 \%$ by limiting the fed rate of glucose during fermentation. Cell densities of both strains reached more than $450\left(\mathrm{OD}_{600 \mathrm{~nm}}\right)$ after $48 \mathrm{~h}$ (Fig. 3a). Productions of secretory proteins synchronized with the cell growths, and all enzymes were dramatically accumulated during the stages from $16 \mathrm{~h}$ to $48 \mathrm{~h}$ (Fig. 3b-d). After $72 \mathrm{~h}$, the IXPaR strain secreted $1664.2 \mathrm{U} / \mathrm{ml}$ of I $\beta$-xylanase and $0.90 \mathrm{U} / \mathrm{ml} \beta$-xylosidase, which were about 28 and 18 folds that of in the flask cultures respectively. SDS-PAGE showed that the IXaR strain secreted two different protein bands that represented mature forms of Xyn-CDBFV and RuXyn1 respectively. The IMPaXPaR strain produced $2210.5 \mathrm{U} / \mathrm{ml}$ of $\beta$-xylanase and $1.25 \mathrm{U} / \mathrm{ml}$ of $\beta$-xylosidase, slightly higher than that of the IXaR strain. As well, this strain also produced $159.8 \mathrm{U} / \mathrm{ml}$ of $\beta$-mannanase concurrently, and all enzymes were secreted extracellularly as their mature forms (Fig. 3e and $\mathrm{f}$ ).

Enzymatic hydrolyses of pretreated corncobs

Hemicellulases supplementation to commercial cellulases enhanced the enzymatic hydrolyses of lignocellulose significantly $[54,55]$. Using prepared hemicellulase cocktails, we next evaluated their 
performances on the promotion of lignocellulose hydrolyses. We chosed corncob as the feedstock for enzymatic hydrolyses because it is one of the most abundant inedible agricultural residues and consists of a relatively high content of hemicellulose ( 40\%) [56]. Enzymatic hydrolyses were conducted with $10 \%(\mathrm{w} / \mathrm{v})$ corncobs pretreated by aqueous dilute acid, and 5 FPU of Cellic ${ }^{\circledR}$ CTec2 cellulase per gram solids. After $96 \mathrm{~h}$, about $300 \mathrm{mM}$ soluble sugars were released from the pretreated corncobs. To test the $\beta$-xylanase Xyn CDBFV and $\beta$-xylosidase RuXy1 performances on the enzymatic hydrolyses, $300 \mu \mathrm{l}$ of supernatant collected from the IXPaR strain fed-batch culture at $48 \mathrm{~h}$, equal to $531.29 \mathrm{U} \beta$-xylanase and $0.22 \cup \beta$-xylosidase, was supplemented to the Cellic ${ }^{\circledR}$ CTec2 cellulase. In accord with previous literatures on pine kraft pulp and softwood $[47,57]$, supplementations of xylanolytic enzymes to the Cellic ${ }^{\circledR}$ CTec2 cellulase improved the enzymatic hydrolysis of corncobs. At each sampling point, addition of the IXPaR strain culture supernatant generated higher contents of soluble sugars. After $96 \mathrm{~h}$ of hydrolysis, the release of soluble sugars increased by $15.7 \%$ (Fig $4 \mathrm{a}$ ). Similarly, the amounts of monomeric glucose and xylose increased to 8.32 and $61.39 \mathrm{~g} / \mathrm{L}$ respectively, which were $11.2 \%$ and $11.1 \%$ higher than that of Cellic ${ }^{\circledR}$ CTec2 cellulase alone (Fig $4 \mathrm{~b}$ and $\mathrm{c}$ ).

The role of $\beta$-mannanase $\mathrm{M} 330$ for the corncob hydrolysis in combination of $\beta$-xylanase and $\beta$-xylosidase was also evaluated. The culture supernatant of IMPaXPaR strain containing $49.50 \mathrm{U} \beta$-mannanase, $485.70 \cup \beta$-xylanase, and $0.28 \cup \beta$-xylosidase was supplemented to the Cellic $\circledast$ CTec2 cellulase. As shown in Figure $4 a$, the supplementary $\beta$-mannanase increased the amount of total soluble sugars over time. At $96 \mathrm{~h}$, about $12.1 \%$ more soluble sugars were obtained comparing to that of the IXPaR strain, and the glucose and xylose contents were increased to 65.48 and $8.45 \mathrm{~g} / \mathrm{L}$ (Fig $4 \mathrm{~b}$ and $\mathrm{c}$ ), which were 11.9\% and $11.4 \%$ higher than that of xylanolytic enzymes respectively, showing that $\beta$-mannanase could facilitate a more extensive break-down of corncobs. This promotion may be ascribed to the deep hydrolysis glucomannan by the endoglucanase TrCel5A presented in Cellic ${ }^{\circledR}$ CTec2 [47].

HSFs of ethanol from pretreated corncobs

Besides the application in expression of heterologous protein, the $K$. marxianus strain used in this study can produce ethanol from multiple substrates, including glucose, xylose, lactose, and inulin, with a maximum ethanol concentration more than $100 \mathrm{~g} / \mathrm{L}[58,59]$. The hemicellulolase activities of IMPaXPaR strain would be conducive to ethanol production from pretreated lignocellulosic biomass. Subsequently, we investigated the potential of recombinant IMPaXPaR strain as a CBP strain to produce ethanol from pretreated corncobs with a high solids content, as it is more economic for cellulosic ethanol processes to generate high sugar titers necessary for high ethanol production $[60,61]$. HSFs were performed by prehydrolyzing pretreated corncobs with $10 \mathrm{FPU}$ commercial cellulase per gram solids for $72 \mathrm{~h}$ before inoculated with the IMPaXPaR or FIM-1 (control) strain. As shown in Figure 5a, glucose in HSFs with IMPaXPaR strain decreased more rapidly than with FIM-1 through the first $96 \mathrm{~h}$. After $216 \mathrm{~h}$, glucose concentrations were 5.2 and $8.7 \mathrm{~g} / \mathrm{L}$ in HSFs with the IMPaXPaR and FIM- 1 strains respectively. The glucose consumption rates in our $K$. marxianus strains were in apparent lower than other $K$. marxianus strains in simultaneous saccharification and fermentation of switchgrass $[4,62,63]$, but the reason for this is not clear. In HSFs with both IMPaXPaR and FIM-1 strain, xylose concentrations increased 
within the first $120 \mathrm{~h}$, and then decreased slightly when prolonging the fermentation time (Fig. 5b). Glucose could strongly repress xylose utilization in simultaneous fermentation of them with $K$. marxianus [64], presumably, responsible for the xylose accumulation during the preceding stage of HSF. Different with the above in vitro saccharification of pretreated corncobs, no significant increase of xylose was found in the HSFs with IMPaXPaR strain comparing to that of FIM-1 strain. The reason may be due to lower glucose concentrations in the HSFs with IMPaXPaR strain that might promote its xylose assimilation.

Ethanol production profiles indicated the IMPaXPaR strain had higher efficiency of ethanol conversion rate, and produced more ethanol during fermentation. At $144 \mathrm{~h}, 20.8 \mathrm{~g} / \mathrm{L}$ of ethanol was obtained in HSFs with IMPaXPaR strain, which is about 34.2\% more than that of FIM-1 (Fig. 5c). After prolonging fermentation time to $216 \mathrm{~h}$, ethanol in HSFs with the IMPaXPaR strain increased to $23.9 \mathrm{~g} / \mathrm{L}$, while it was $21.3 \mathrm{~g} / \mathrm{L}$ in that of FIM-1 strain. Considering the high glucose consumption rate in HSFs with IMPaXPaR strain, we used the sugar-ethanol conversion rates based on their initial glucose contends to present the contribution of hemicellulases produced for ethanol production. As shown in Figure $5 d$, the ethanol conversion rates of IMPaXPaR strain at 144, 168, 192, and $216 \mathrm{~h}$ were $0.54,0.55,0.55$, and 0.55, respectively, which were higher than the theoretical ethanol conversion rate 0.51 from glucose, indicating additional amounts of glucose were produced during fermentation. While, at the same points, ethanol conversion rates for the control strain were $0.51,0.51,0.51$, and 0.52 respectively. Consequently, we confirmed that the hemicellulolytic enzymes produced by IMPaXPaR strain improved the hydrolysis and ethanol conversion in HSFs of pretreated corncobs.

\section{Conclusions}

The FMDV P2A showed high efficiency in self-cleavage of the polyprotein in K. marxianus, and could be used for secretory co-expression of multiple enzymes. Supplements of hemicellulolytic enzymes prepared by the IMPaX and IMPaXPaR strains to commercial cellulases increased both glucose and xylose yields from diluted acid pretreated corncobs. The IMPaXPaR strain that coordinately secreted three hemicellulolytic enzymes, including a $\beta$-mannanase M330, a $\beta$-xylanase Xyn CDBFV, and $\beta$-xylosidase RuXyn1, produced 21.3 and $23.9 \mathrm{~g}$ ethanol at 144 and $216 \mathrm{~h}$ from pretreated corncobs, which were $34.2 \%$ and $11.1 \%$ higher than that of its parent strain respectively, showing that it is a useful CBP strain for ethanol production in HSF processes.

\section{Abbreviations}

CBP: consolidated bioprocessing; HSF: hybrid saccharification and fermentation; SSF: simultaneous saccharification and fermentation; FMDV: Foot-and-Mouth Disease virus; DO: the dissolved oxygen; WCW: wet cell weights; FPU: filter paper unit; ORF: open read frame; IRES: the internal ribosomal entry site.

\section{Declarations}


Acknowledgements

Not applicable.

\section{Funding}

This project was sponsored by National Natural Science Foundation of China (31200022, 31770094, and 31970068), National High Technology Research and Development Program of China (2014AA021301), and Science and Technology Research Program of Shanghai (19DZ2282100).

\section{Contributions}

JZ and HL conceived the study and wrote the manuscript. QL, YD, PW, and XL performed the experiments, acquisition and interpretation of data. YY, BS, JZ, and QL guided the study, analyzed the data, and edited the manuscript. All authors read and approved the final manuscript.

\section{Corresponding authors}

Correspondence to Jungang Zhou or Hong Lu.

\section{Ethics declarations}

\section{Ethics approval and consent to participate}

Not applicable.

\section{Consent for publication}

All authors have given their consent for the publication.

\section{Conflict of Interest}

The authors declare that they have no competing interests.

\section{Availability of data and materials}

All data generated or analyzed during this study are included in this published article.

\section{References}

1. Lorenci Woiciechowski A, et al. Lignocellulosic biomass: Acid and alkaline pretreatments and their effects on biomass recalcitrance - Conventional processing and recent advances. Bioresour Technol. 2020;304:122848.

2. Francois JM, et al. Engineering microbial pathways for production of bio-based chemicals from lignocellulosic sugars: current status and perspectives. Biotechnol Biofuels. 2020;13:118. 
3. Mosier N, et al. Features of promising technologies for pretreatment of lignocellulosic biomass. Bioresour Technol. 2005;96(6):673-86.

4. Faga BA, et al. Ethanol production through simultaneous saccharification and fermentation of switchgrass using Saccharomyces cerevisiae D(5)A and thermotolerant Kluyveromycesmarxianus IMB strains. Bioresour Technol. 2010;101(7):2273-9.

5. Alvira $P$, et al. Effect of endoxylanase and alpha-L-arabinofuranosidase supplementation on the enzymatic hydrolysis of steam exploded wheat straw. Bioresour Technol. 2011;102(6):4552-8.

6. Lynd LR, et al. How biotech can transform biofuels. Nat Biotechnol. 2008;26(2):169-72.

7. Shi J, et al. Dynamic changes of substrate reactivity and enzyme adsorption on partially hydrolyzed cellulose. Biotechnol Bioeng. 2017;114(3):503-15.

8. Jiang Y, et al. Consolidated bioprocessing performance of a two-species microbial consortium for butanol production from lignocellulosic biomass. Biotechnol Bioeng. 2020;117(10):2985-95.

9. Kim SM, et al. Promise of combined hydrothermal/chemical and mechanical refining for pretreatment of woody and herbaceous biomass. Biotechnol Biofuels. 2016;9:97.

10. Chang JJ, et al. Constructing a cellulosic yeast host with an efficient cellulase cocktail. Biotechnol Bioeng. 2018;115(3):751-61.

11. Liu H, et al. Engineering microbes for direct fermentation of cellulose to bioethanol. Crit Rev Biotechnol. 2018:1-17.

12. Branduardi $P$, et al. The yeast : a new host for heterologous protein production, secretion and for metabolic engineering applications. FEMS Yeast Research. 2004;4(4-5):493-504.

13. Liu $\mathrm{H}$, et al. Engineering microbes for direct fermentation of cellulose to bioethanol. Crit Rev Biotechnol. 2018;38(7):1089-105.

14. Lassmann T, et al. Simulation of the downstream processing in the ethanol production from lignocellulosic biomass with ASPEN Plus ${ }^{\circledR}$ and IPSEpro. Energy, Sustainability and Society. 2014;4(1).

15. Binder JB, Raines RT. Fermentable sugars by chemical hydrolysis of biomass. Proc Natl Acad Sci U S A. 2010;107(10):4516-21.

16. Matsushika A, et al. Ethanol production from xylose in engineered Saccharomyces cerevisiae strains: current state and perspectives. Appl Microbiol Biotechnol. 2009;84(1):37-53.

17. Fonseca GG, et al. The yeast Kluyveromyces marxianus and its biotechnological potential. Appl Microbiol Biotechnol. 2008;79(3):339-54.

18. Radecka D, et al. Looking beyond Saccharomyces: the potential of non-conventional yeast species for desirable traits in bioethanol fermentation. FEMS Yeast Res. 2015;15(6).

19. Zhou J, et al. Improved secretory expression of lignocellulolytic enzymes in Kluyveromyces marxianus by promoter and signal sequence engineering. Biotechnol Biofuels. 2018;11:235.

20. Mehmood N, et al. Kluyveromyces marxianus, an Attractive Yeast for Ethanolic Fermentation in the Presence of Imidazolium lonic Liquids. Int J Mol Sci. 2018;19(3). 
21. Castro RC, Roberto IC. Selection of a thermotolerant Kluyveromyces marxianus strain with potential application for cellulosic ethanol production by simultaneous saccharification and fermentation. Appl Biochem Biotechnol. 2014;172(3):1553-64.

22. Lobs AK, et al. CRISPR-Cas9-enabled genetic disruptions for understanding ethanol and ethyl acetate biosynthesis in Kluyveromyces marxianus. Biotechnol Biofuels. 2017;10:164.

23. Chang JJ,et al. PGASO: A synthetic biology tool for engineering a cellulolytic yeast. Biotechnol Biofuels. 2012;5(1):53.

24. Choo JH, et al. Deletion of a KU80 homolog enhances homologous recombination in the thermotolerant yeast Kluyveromyces marxianus. Biotechnol Lett. 2014;36(10):2059-67.

25. Abdel-Banat BM, et al. Random and targeted gene integrations through the control of nonhomologous end joining in the yeast Kluyveromyces marxianus. Yeast. 2010;27(1):29-39.

26. Nonklang $S$, et al. High-temperature ethanol fermentation and transformation with linear DNA in the thermotolerant yeast Kluyveromyces marxianus DMKU3-1042. Appl Environ Microbiol. 2008;74(24):7514-21.

27. Fang J, et al. Stable antibody expression at therapeutic levels using the $2 \mathrm{~A}$ peptide. Nat Biotechnol. 2005;23(5):584-90.

28. Ryan MD, et al. Analysis of the aphthovirus $2 \mathrm{~A} / 2 \mathrm{~B}$ polyprotein 'cleavage' mechanism indicates not a proteolytic reaction, but a novel translational effect: a putative ribosomal 'skip'. J Gen Virol 2001;82(5):1013-25.

29. de Felipe $P$, et al. Co-translational, intraribosomal cleavage of polypeptides by the foot-and-mouth disease virus 2A peptide. J Biol Chem. 2003;278(13):11441-8.

30. Chen Y-L, et al. Directed evolution to produce an alkalophilic variant from a Neocallimastix patriciarum xylanase. Can J Microbiol. 2001;47(12):1088-94.

31. You C, et al. Potential hydrophobic interaction between two cysteines in interior hydrophobic region improves thermostability of a family 11 xylanase from Neocallimastix Patriciarum. Biotechnol Bioeng. 2010;105(5):861-70.

32. Gibson, et al. Enzymatic assembly of DNA molecules up to several hundred kilobases. Nat Methods. 2009.

33. Zhou J, et al. Biochemical and kinetic characterization of GH43 beta-D-xylosidase/alpha-Larabinofuranosidase and GH30 alpha-L-arabinofuranosidase/beta-D -xylosidase from rumen metagenome. J Ind Microbiol Biotechnol. 2012;39(1):143-52.

34. Antunes DF, et al. A simple and rapid method for lithium acetate-mediated transformation of Kluyveromyces marxianus cells. World J Microbiol Biotechnol. 2000;16(7):653-4.

35. Pan X, et al. High level expression of a truncated beta-mannanase from alkaliphilic Bacillus sp. N165 in Kluyveromyces cicerisporus. Biotechnol Lett. 2011;33(3):565-70.

36. Miller GL. Use of Dinitrosalicylic Acid Reagent for Determination of Reducing Sugar. Anal Chem. 1959;31(3):426-8. 
37. Shallom D, Shoham Y. Microbial hemicellulases. Curr Opin Microbiol. 2003;6(3):219-28.

38. Doronina VA, et al. Site-specific release of nascent chains from ribosomes at a sense codon. Mol Cell Biol. 2008;28(13):4227-39.

39. Souza-Moreira TM, et al. Screening of 2A peptides for polycistronic gene expression in yeast. FEMS Yeast Res. 2018;18(5).

40. Roongsawang $\mathrm{N}$, et al. Coexpression of fungal phytase and xylanase utilizing the cis-acting hydrolase element in Pichia pastoris. FEMS Yeast Res. 2010;10(7):909-16.

41. Trichas $\mathrm{G}$, et al. Use of the viral $2 \mathrm{~A}$ peptide for bicistronic expression in transgenic mice. BMC Biol. 2008;6:40.

42. Ohgren $\mathrm{K}$, et al. Effect of hemicellulose and lignin removal on enzymatic hydrolysis of steam pretreated corn stover. Bioresour Technol. 2007;98(13):2503-10.

43. García-Aparicio MP, et al. Xylanase contribution to the efficiency of cellulose enzymatic hydrolysis of barley straw. Appl Biochem Biotechnol. 2007;137-140(1-12):353-65.

44. Várnai $A$, et al. Restriction of the enzymatic hydrolysis of steam-pretreated spruce by lignin and hemicellulose. Enzy Microbial Technol. 2010;46(3-4):185-93.

45. Saitoh S, et al. Co-fermentation of cellulose/xylan using engineered industrial yeast strain OC-2 displaying both beta-glucosidase and beta-xylosidase. Appl Microbiol Biotechnol. 2011;91(6):1553-9.

46. Banerjee $G$, et al. Rapid optimization of enzyme mixtures for deconstruction of diverse pretreatment/biomass feedstock combinations. Biotechnol Biofuels. 2010;3:22.

47. Varnai $A$, et al. Synergistic action of xylanase and mannanase improves the total hydrolysis of softwood. Bioresour Technol. 2011;102(19):9096-104.

48. Inoue $\mathrm{H}$, et al. Effect of beta-Mannanase and beta-Mannosidase Supplementation on the Total Hydrolysis of Softwood Polysaccharides by the Talaromyces cellulolyticus Cellulase System. Appl Biochem Biotechnol. 2015;176(6):1673-86.

49. Katsimpouras C, et al. A thermostable GH26 endo-beta-mannanase from Myceliophthora thermophila capable of enhancing lignocellulose degradation. Appl Microbiol Biotechnol. 2016;100(19):8385-97.

50. Cornelis, et al. Effect of benzoic acid on metabolic fluxes in yeasts: A continuous-culture study on the regulation of respiration and alcoholic fermentation. Yeast. 1992.

51. Karim A, et al. Kluyveromyces marxianus: An emerging yeast cell factory for applications in food and biotechnology. Int J Food Microbiol. 2020;333:108818.

52. Postma E, et al. Enzymic analysis of the crabtree effect in glucose-limited chemostat cultures of Saccharomyces cerevisiae. Appl Environl Microbiol. 1989;55(2):468.

53. Dashko $S$, et al. Why, when, and how did yeast evolve alcoholic fermentation? FEMS Yeast Res. 2014;14(6):826-32.

54. Remond C, et al. Combination of ammonia and xylanase pretreatments: impact on enzymatic xylan and cellulose recovery from wheat straw. Bioresour Technol. 2010;101(17):6712-7. 
55. Shin HD, et al. Novel Aspergillus hemicellulases enhance performance of commercial cellulases in lignocellulose hydrolysis. Biotechnol Prog. 2011;27(2):581-6.

56. Liu K, et al. High concentration ethanol production from corncob residues by fed-batch strategy. Bioresour Technol. 2010;101(13):4952-8.

57. Tenkanen $M$, et al. Investigation of lignin-carbohydrate complexes in kraft pulps by selective enzymatic treatments. Appl Microbiol Biotechnol. 1999;51(2):241-8.

58. Gao J, et al. Transcriptional analysis of Kluyveromyces marxianus for ethanol production from inulin using consolidated bioprocessing technology. Biotechnol Biofuels. 2015;8:115.

59. Mo W, et al. Kluyveromyces marxianus developing ethanol tolerance during adaptive evolution with significant improvements of multiple pathways. Biotechnol Biofuels. 2019;12:63.

60 . Hodge DB, et al. Soluble and insoluble solids contributions to high-solids enzymatic hydrolysis of lignocellulose. Bioresour Technol. 2008;99(18):8940-8.

61. Humbird D, et al. Economic impact of total solids loading on enzymatic hydrolysis of dilute acid pretreated corn stover. Biotechnol Prog. 2010;26(5):1245-51.

62. Pessani NK, et al. Simultaneous saccharification and fermentation of Kanlow switchgrass by thermotolerant Kluyveromyces marxianus IMB3: the effect of enzyme loading, temperature and higher solid loadings. Bioresour Technol. 2011;102(22):10618-24.

63. Suryawati L, et al. Simultaneous saccharification and fermentation of Kanlow switchgrass pretreated by hydrothermolysis using Kluyveromyces marxianus IMB4. Biotechnol Bioeng. 2008;101(5):894902.

64. Hua Y, et al. Release of glucose repression on xylose utilization in Kluyveromyces marxianus to enhance glucose-xylose co-utilization and xylitol production from corncob hydrolysate. Microb Cell Fact. 2019;18(1):24.

\section{Tables}

\section{Table1: Primer sequences used in this work}




\begin{tabular}{|c|c|}
\hline Primers & Sequences \\
\hline MF & ATGAAGTTAGCATACTCCСTCTTGC \\
\hline IMXR1 & GAACTACAGAAACTTTGTGTAAATACGGTGGATGGTTTGGAG \\
\hline IMXF & TCCACCGTATTTACACAAAGTTTCTGTAGTTCAGCTTCTC \\
\hline $\mathrm{XR}$ & CTAGTGATGATGATGATGGTGATCACCAATGTAAACCTTTGCGTATGG \\
\hline IMPR & $\begin{array}{l}\text { AGGACCGGGGTTTTCTTCCACGTCTCCTGCTTGCTTTAACAGAGAGAAGT } \\
\text { TCGTGGCTCCGGATCCTGTAAATACGGTGGATGGTTTGGA }\end{array}$ \\
\hline IMPXF & TGGAAGAAAACCCCGGTCCTCAAAGTTTCTGTAGTTCAGCTTCTCACT \\
\hline PaF1 & GGAAGAAAACCCCGGTCCTATGAGATTTCCTTCAATTTTTACTGCAG \\
\hline aXR1 & GAGAAGCTGAACTACAGAAACTTTGCCCGGGTACGTAAGCTTCAGCCTCT \\
\hline aXF1 & AGAGGCTGAAGCTTACGTACCCGGGCAAAGTTTCTGTAGTTCAGCTTCTC \\
\hline XPR & ATCACCAATGTAAACCTTTGCGTATG \\
\hline $\mathrm{XPaF}$ & ACGCAAAGGTTTACATTGGTGATGGATCCGGAGCCACGAACTTCTCTC \\
\hline aR1 & ATAGCGTTTCTTAACTTTATCAGCCCCGGGTACGTAAGCTTCAGCCTCT \\
\hline aRF & TGATAAAGTTAAGAAACGCTAT \\
\hline RR & CAAAGCTTGCGGCCTTAAGCGGCCGCTTACTCATCCATGCCTTCGATGGTG \\
\hline IXF & AGACGGTGACCCCGGGACTAGTATGAGATTTCCTTCAATTTTTACTG \\
\hline
\end{tabular}

Table 2 The $\beta$-mannanase and $\beta$-xylanase activities of the IMX, IMPX, and IMPaX strains cultured in flasks at $30^{\circ} \mathrm{C}, 220 \mathrm{rpm}$ for $72 \mathrm{~h}$.

\begin{tabular}{|lllll|}
\hline \multirow{2}{*}{ Strains } & \multicolumn{2}{l}{$\beta$-Mannanase activities } & \multicolumn{2}{l|}{$\beta$-Xylanase activities } \\
\cline { 2 - 5 } & Extracellular & Intracellular & Extracellular & Intracellular \\
\hline IMX & $24.03 \pm 3.74$ & $1.13 \pm 0.19$ & $155.26 \pm 4.24$ & $44.17 \pm 4.24$ \\
\hline IMPX & $21.34 \pm 1.37$ & $4.50 \pm 0.75$ & $42.07 \pm 4.99$ & $87.59 \pm 11.41$ \\
\hline IMPaX & $15.50 \pm 1.91$ & $4.62 \pm 0.44$ & $136.17 \pm 15.34$ & $39.43 \pm 4.11$ \\
\hline
\end{tabular}

\section{Figures}



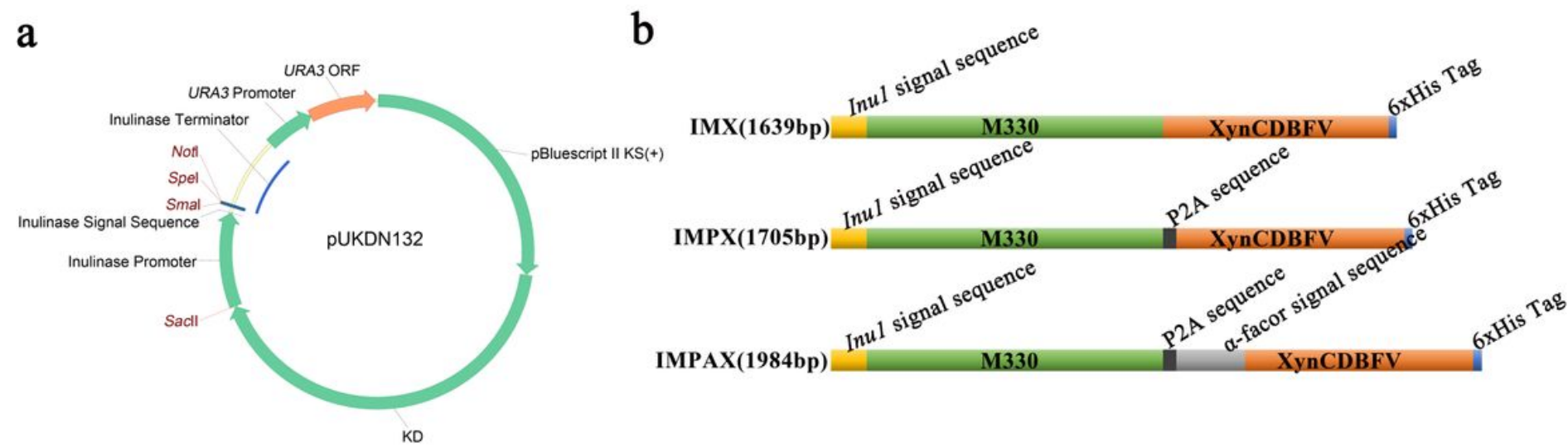

c
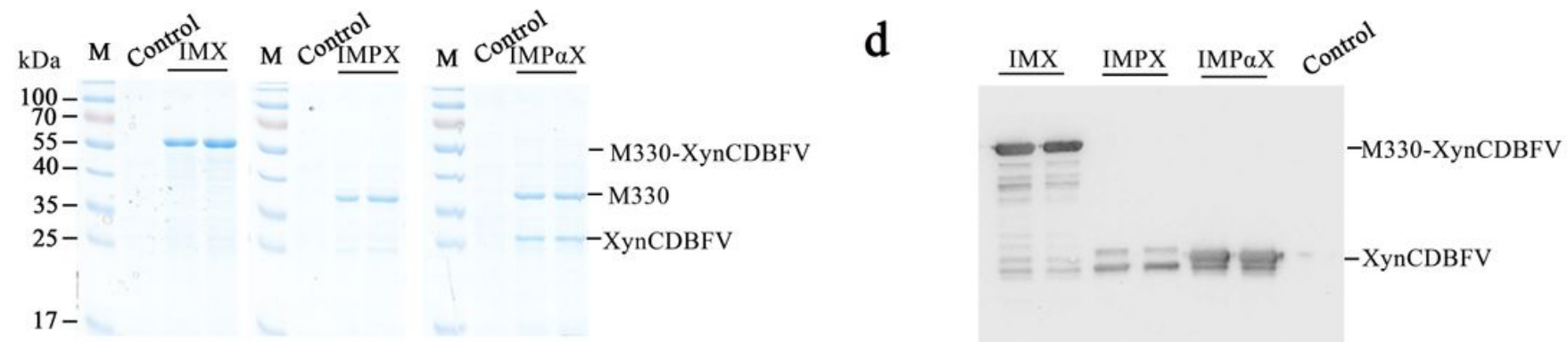

e
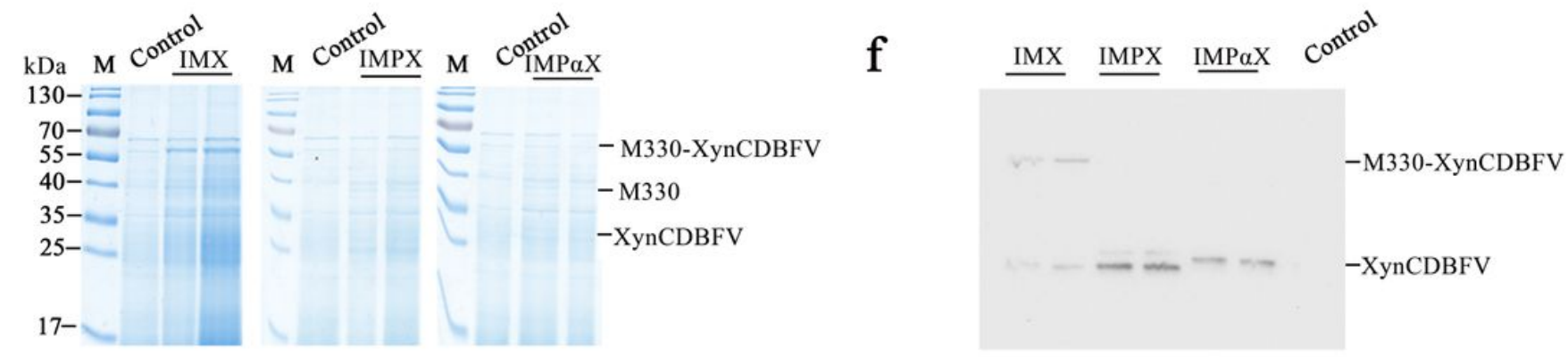

\section{Figure 1}

The efficiency of FMDV P2A in self-cleavage of M330 and XynCBDFV. a Map of the expression vector pUKDN132; $b$ Illustrations of the polycistronic genes IMX, IMPX, and IMPaX; SDS-PAGE and western blots of the supernatants (c and d) and cell lysates (e and f) of flask cultures. 


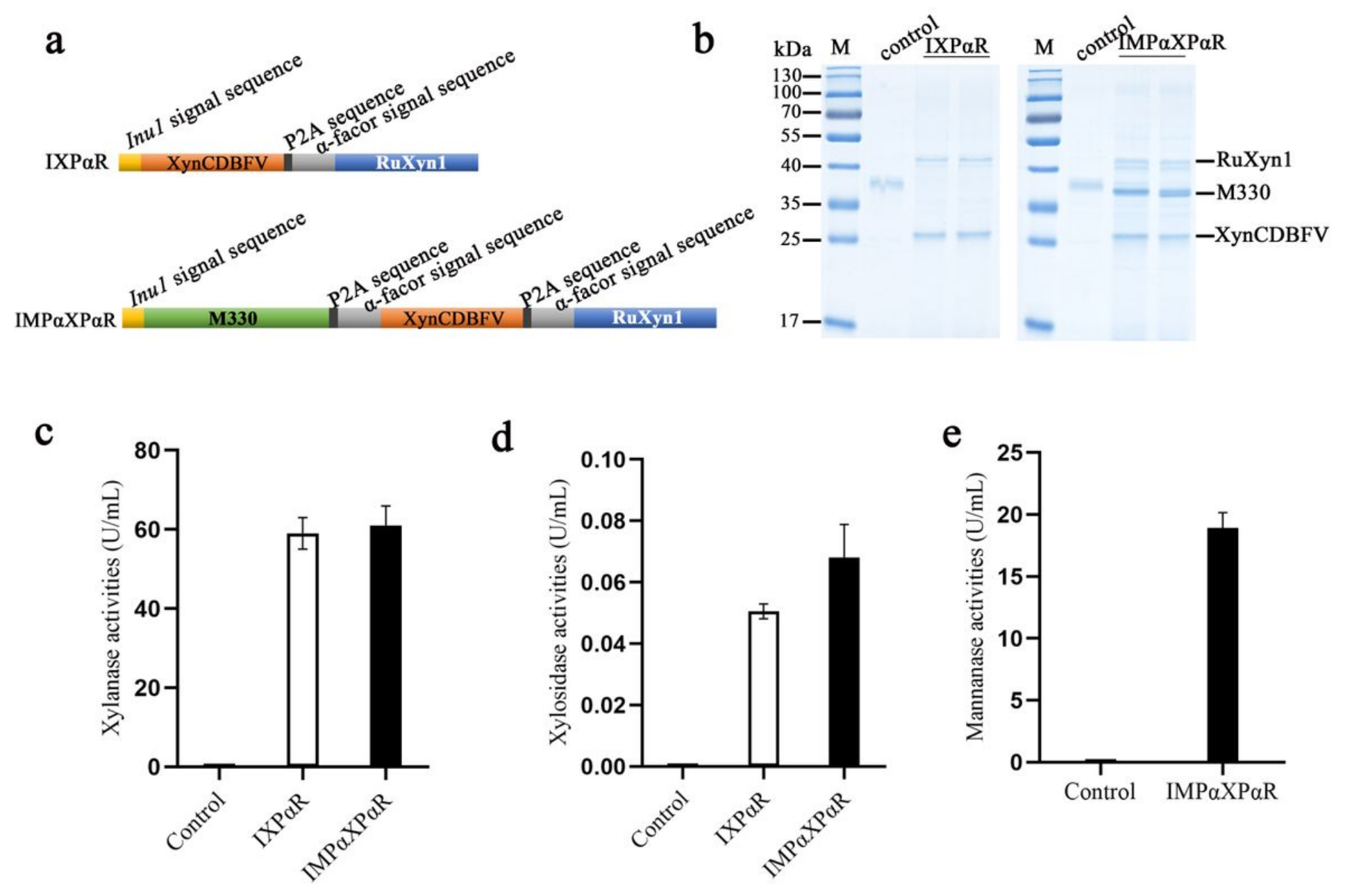

Figure 2

Secretory expression of hemicellulolytic enzymes in K. marxianus. a Constructions of the polycistronic genes IMPaX and IMPaXPaR; SDS-PAGE (b) and activities of $\beta$-xylanase (c), $\beta$-xylosidase (d), and $\beta$ mannanase (e) for the supernatants of IMPaX and IMPaXPaR strains. 
a

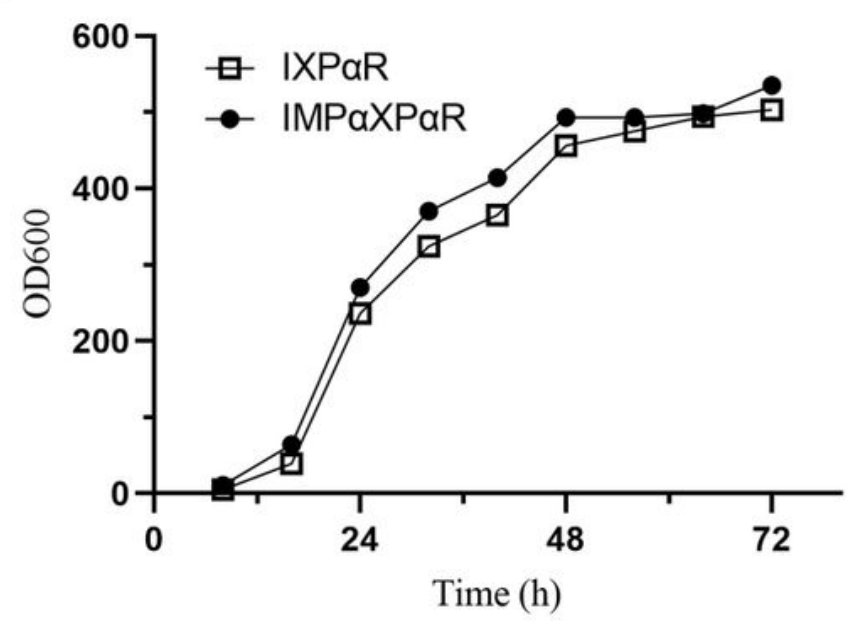

C

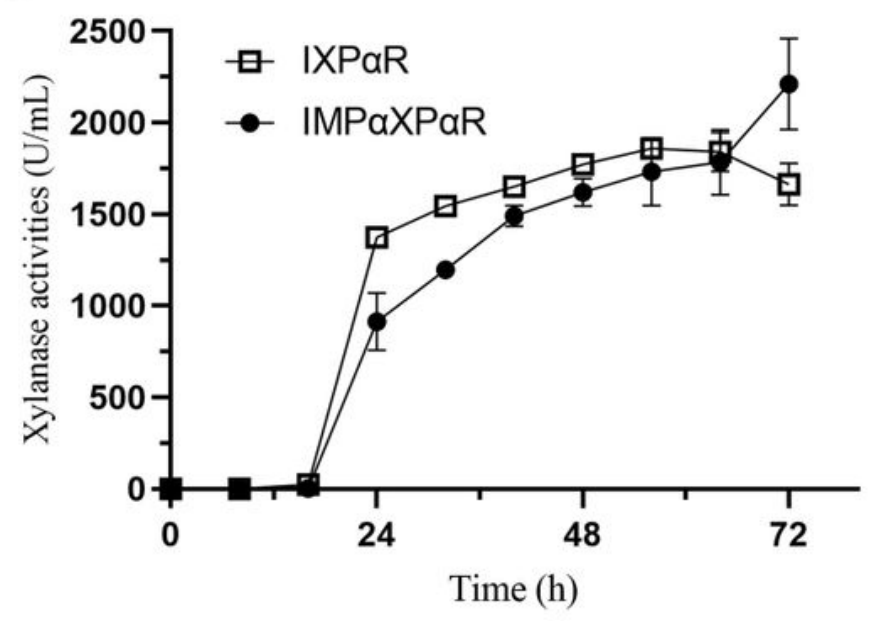

e

Time (h)

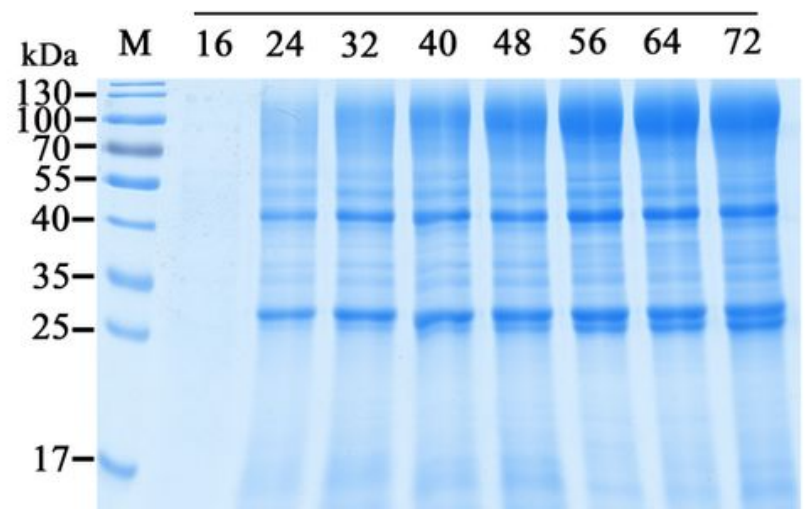

b

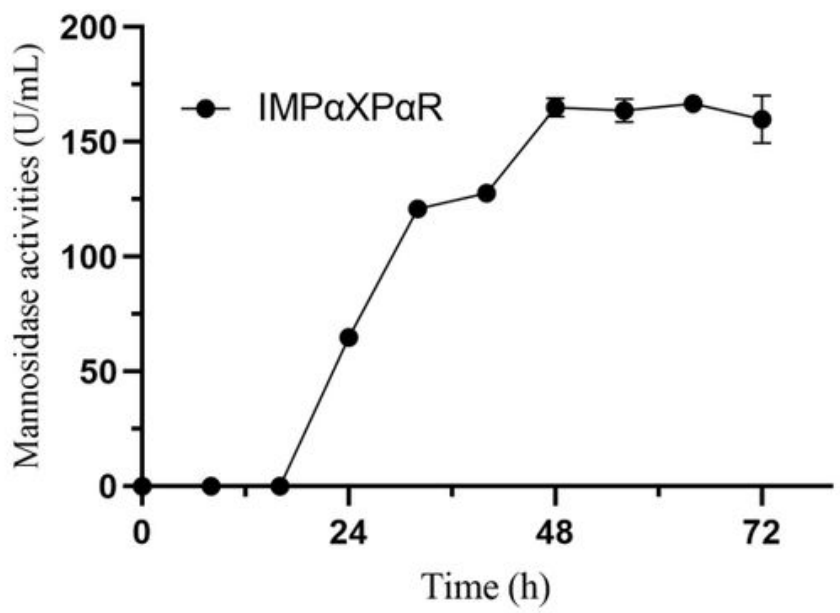

d

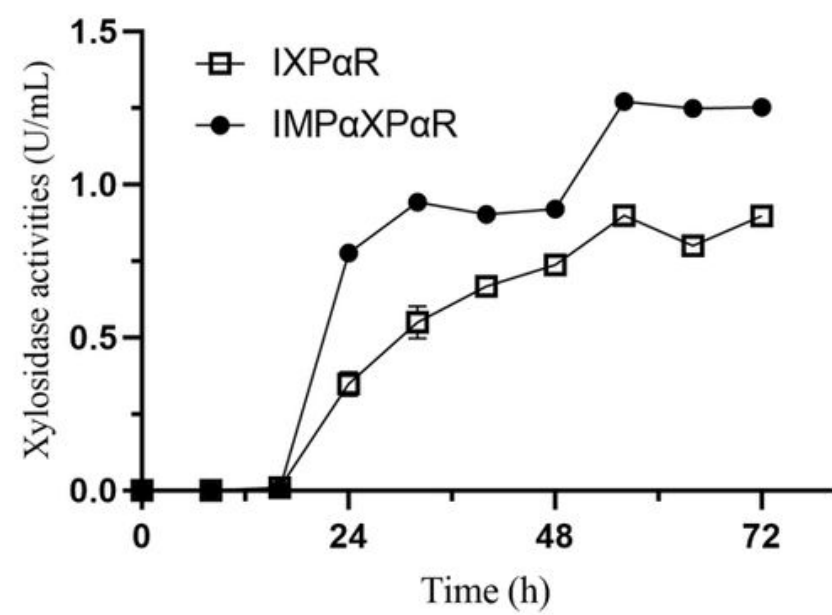

f

Time (h)

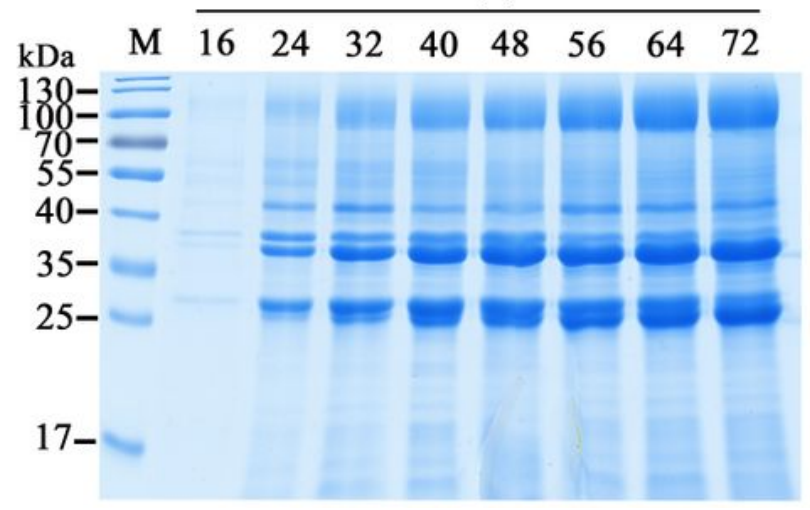

\section{Figure 3}

Growth curves (a) and productions of $\beta$-mannanase (b), $\beta$-xylanase (c), and $\beta$-xylosidase (d) in fed-batch fermentation of the IMPaX and IMPaXPaR strains. Supernatant samples at the indicated times of of the $\operatorname{IMPaX}(\mathrm{e})$ and IMPaXPaR strains were also analyzed by SDS-PAGE. 

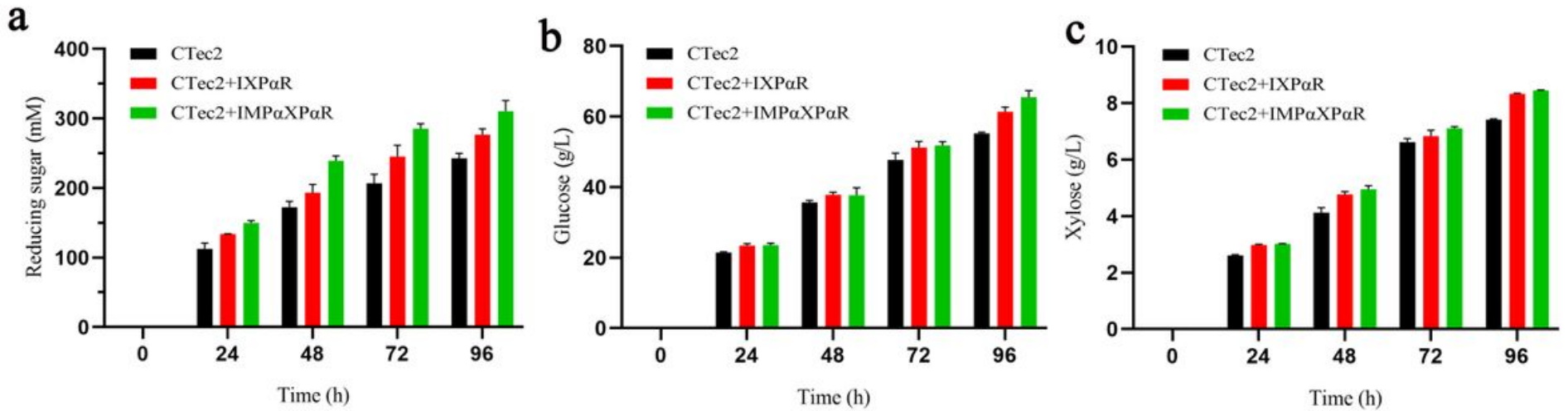

Figure 4

Concentrations of the reducing sugars (a), glucose (b), and xylose (c) over time in the hydrolysis of pretreated corncobs.

a

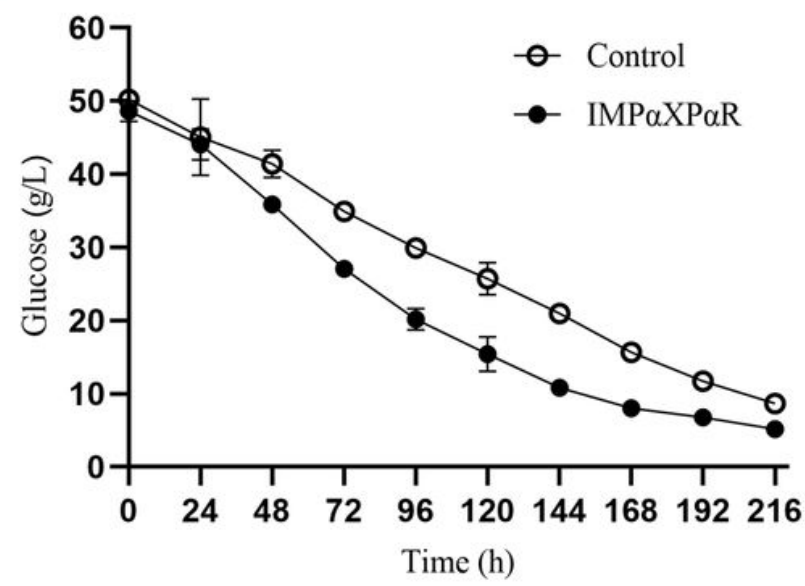

C

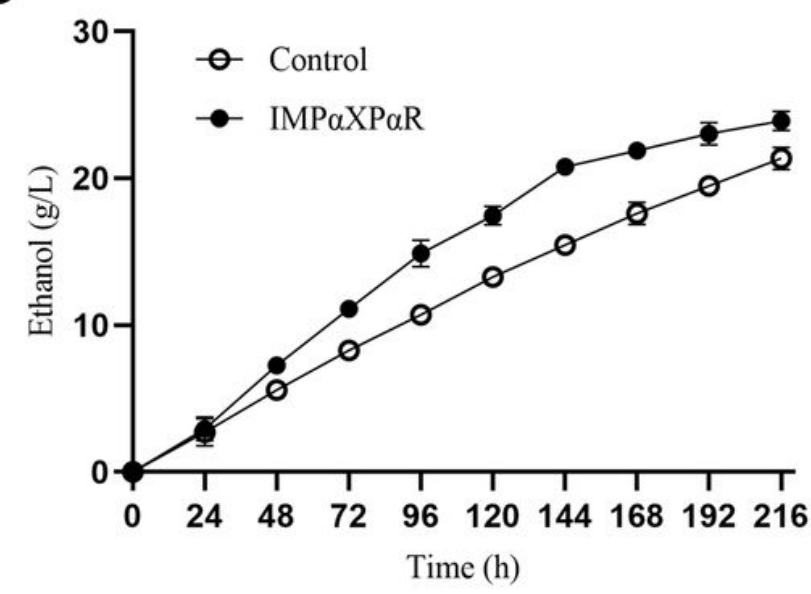

b

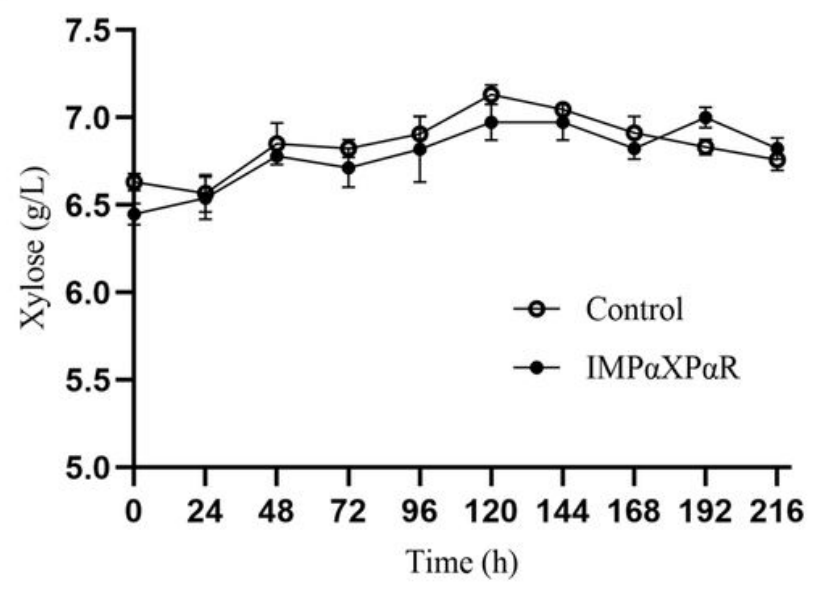

d

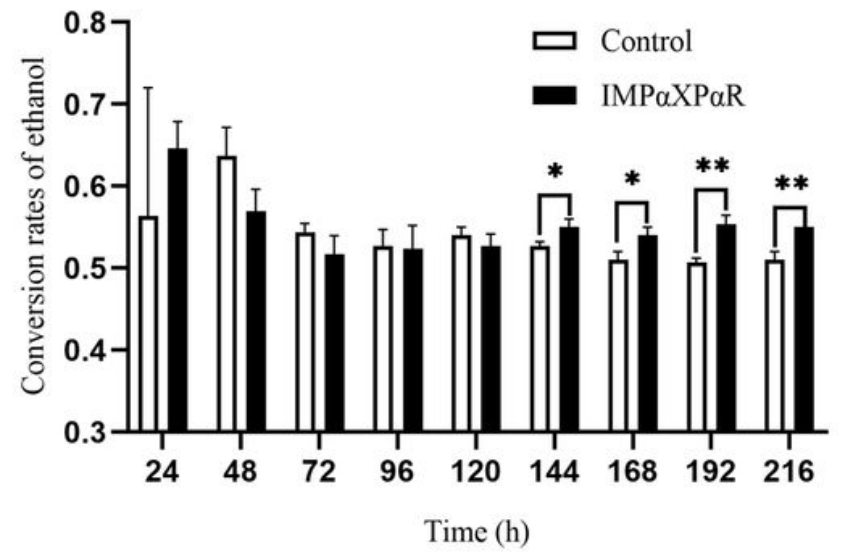

Figure 5 
Concentrations of glucose (a), xylose (b), and ethanol (c), and sugar-ethanol conversion rates (d) during HSFs with the IMPaXPaR and Fim-1 (control) strains. Conversion rates were calculated as following: ethanol yields / (initial glucose concentration-residual glucose concentration). *, $p<0.05 ;{ }^{* \star}, p<0.01$. 